\title{
Amorphous Alloy: Promising Precursor to Form Nanoflowerpot
}

\author{
Guo Lan, Zhiqiang Xie, Zhenwei Huang, Shengchen Yang, Xuhai Zhang, \\ Yuqiao Zeng, and Jianqing Jiang \\ Jiangsu Key Laboratory of Advanced Metallic Materials, School of Materials Science and Engineering, Southeast University, \\ Nanjing 211189, China \\ Correspondence should be addressed to Yuqiao Zeng; zyuqiao@hotmail.com
}

Received 7 March 2014; Accepted 23 April 2014; Published 20 May 2014

Academic Editor: $\mathrm{Na}$ Chen

Copyright (C) 2014 Guo Lan et al. This is an open access article distributed under the Creative Commons Attribution License, which permits unrestricted use, distribution, and reproduction in any medium, provided the original work is properly cited.

Nanoporous copper is fabricated by dealloying the amorphous $\mathrm{Ti}_{2} \mathrm{Cu}$ alloy in $0.03 \mathrm{M} \mathrm{HF}$ electrolyte. The pore and ligament sizes of the nanoporous copper can be readily tailored by controlling the dealloying time. The as-prepared nanoporous copper provides fine and uniform nanoflowerpots to grow highly dispersed Au nanoflowers. The blooming Au nanoflowers in the nanoporous copper flowerpots exhibit both high catalytic activity and stability towards the oxidation of glucose, indicating that the amorphous alloys are ideal precursors to form nanoflowerpot which can grow functional nanoflowers.

\section{Backgrounds}

Owing to the unique combination of physical, chemical, and mechanical properties, amorphous alloys have been posed as promising new materials for structural and functional utilizations $[1,2]$. One of the most attractive applications is to use the amorphous alloys in nanotechnology. If the amorphous alloy is in a glassy state, the supercooled liquid region where the Newton's flow can take place may provide fascinating fabrication capability for the alloys. Nanorods, nanobars, and even mircogears have been successfully prepared by nanoimprinting in the supercooled liquid region of Zr-based and Pt-based amorphous alloys [3, 4]. However, the amorphous alloys which have large supercooled liquid region are quite limited. Dealloying, on the other hand, can be performed on most of the amorphous alloys to form uniform nanostructure, no matter the alloy exhibits supercooled liquid region or not. During dealloying, the less noble elements are selectively dissolved and noble element keeps self-assembling through surface diffusion, leaving behind a bicontinuous nanoporous (NP) structure [5]. Usually, dealloying is applied on crystalline alloys composed by a single phase, such as intermetallic compounds or solid solutions, to form NP metals which have various functional applications in catalysis, chemical sensors, and electrochemistry [6-9]. Recently, there are some attempts to form nanoporous alloy by dealloying amorphous alloys and the results show that the nanoporous structure obtained by dealloying amorphous alloy was finer and more uniform than that obtained by dealloying crystalline alloys. Therefore, there are intensive interests in the catalytic, thermal, and optical applications of the NP materials prepared by dealloying amorphous alloys. For instance, Yu et al. synthesized NPPd by electrochemically dealloying the $\mathrm{Pd}_{30} \mathrm{Ni}_{50} \mathrm{P}_{20}$ amorphous alloy [10] and Lang et al. prepared NPAu by dealloying the Au-based amorphous alloy [11]. These NP materials exhibited high catalytic activity towards the oxidation of formic acid. Luo et al. obtained NP copper (NPC) by dealloying AlCuMg amorphous alloys. The NPC had extremely high specific surface area and could be used as low-temperature heat exchanger [12]. However, to our knowledge, there is no report on growing functional nanoflowers on the fine and uniform NP structures which are prepared by dealloying amorphous alloys.

In this study, we use $\mathrm{Ti}_{2} \mathrm{Cu}$ amorphous alloy as the dealloying precursor to form "nanoflowerpot" to grow $\mathrm{Au}$ nanoflowers. Au in a nanoarchitecture form, such as NPAu, $\mathrm{Au}$ nanoflower, and $\mathrm{Au}$ nanoparticle, is an ideal material for enzyme-free electrochemical glucose sensor due to the high catalytic activity towards the oxidation of glucose [13, 14]. However, most of the $\mathrm{Au}$ nanomaterials suffer from the structure degradation [15]. For instance, nanopores and ligaments in NPAu will get coarsened and finally lose the 


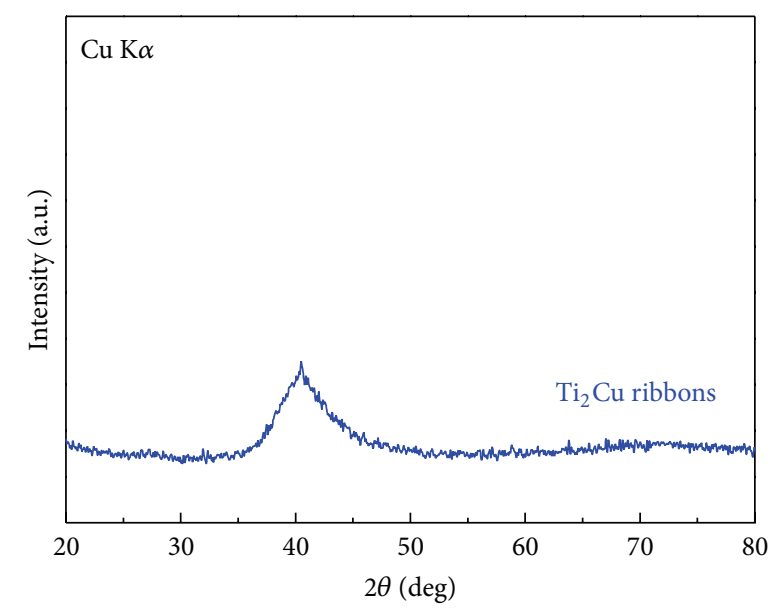

FIGURE 1: XRD pattern of the as-prepared $\mathrm{Ti}_{2} \mathrm{Cu}$ ribbon sample.

catalytic activity during catalysis. It is expected that when NPC is used as the flowerpots to grow $\mathrm{Au}$ nanoflowers, that NPC dealloyed from amorphous alloy can provide homogenous dispersed growing sites for Au and stabilize the catalytic activity of the Au nanoflowers.

\section{Experimental Methods}

The $\mathrm{Ti}_{2} \mathrm{Cu}$ amorphous alloy ribbon was prepared by arc melting $\mathrm{Ti}$ and $\mathrm{Cu}$ metals in a high-purity argon gas atmosphere, followed by melt spinning with a copper wheel velocity of about $40 \mathrm{~ms}^{-1}$. The as-prepared amorphous ribbon is about $20 \mathrm{um}$ in thickness and $1 \mathrm{~mm}$ in width. The XRD pattern of the ribbon was recorded using an X-ray diffractometer with $\mathrm{Cu}$ Ka radiation.

NPC samples are fabricated by selective etching of the $\mathrm{Ti}_{2} \mathrm{Cu}$ amorphous ribbons in $0.03 \mathrm{M}$ HF solutions. The dealloyed samples were firstly rinsed in pure water more than three times to remove the residual chemical substances and then were dried by freeze drier. With the aim of growing Au nanoflowers with tunable size, the dried NPC was immersed into a $0.5 \mathrm{mM} \mathrm{HAuCl}_{4}$ solution in a three-neck flask at $0^{\circ} \mathrm{C}$ under Ar-protected magnetic stirring conditions.

The microstructures of the NPC as well as the NPC-G were observed by field-emission scanning electron microscope (SEM) and the compositions were characterized by energy dispersive X-ray spectrometer (EDS). The electrochemical performance of the NPC-G towards the oxidation of d-glucose is tested by electrochemical workstation CHI760D, where the NPC-G was used as the working electrode, saturated calomel electrode was used as a reference electrode, and a Pt foil was used as the counter electrode. The electrolyte is mixed with $0.01 \mathrm{M}$ PBS and $50 \mathrm{mM}$ glucose.

\section{Results and Discussion}

The XRD pattern of the ribbon in Figure 1 shows only a broad diffraction maximum without any observable crystalline peaks, demonstrating the formation of a homogenous amorphous structure in the ribbon sample.
TABLE 1: Chemical compositions of the NPC samples test by EDS.

\begin{tabular}{lcc}
\hline Sample number & $\mathrm{Cu}($ at\%) & $\mathrm{Ti}$ (at\%) \\
\hline Amorphous ribbon & 33.3 & 66.7 \\
NPC number 1 & 85.3 & 14.7 \\
NPC number 2 & 99.0 & 1.0 \\
NPC number 3 & 99.5 & 0.5 \\
\hline
\end{tabular}

TABLE 2: Chemical compositions of the NPC-G samples test by EDS.

\begin{tabular}{lcc}
\hline Sample number & $\mathrm{Au}(\mathrm{at} \%)$ & $\mathrm{Cu}(\mathrm{at} \%)$ \\
\hline NPC-G number 1 & 87.2 & 12.8 \\
NPC-G number 2 & 95.9 & 4.1 \\
NPC-G number 3 & 96.9 & 3.1 \\
\hline
\end{tabular}

When the $\mathrm{Ti}_{2} \mathrm{Cu}$ amorphous alloy is used as the precursor, the morphology development with the dealloying time is observed by SEM and the corresponding images are shown in Figure 2. Three-dimensional, interpenetrating ligamentchannel nanoporous structure can be seen after $1 \mathrm{~h}$ of etching (Figure 2(a)). The ligaments are in a size ranging within 50$100 \mathrm{~nm}$ and the nanopores are about $5-20 \mathrm{~nm}$. $10 \mathrm{~h}$ of etching leads to the formation of a fine continuous nanoporous structure. The ligaments are about $50-100 \mathrm{~nm}$ in size and the pores are in a bimodal distribution; that is, small pores are about $5 \mathrm{~nm}$ and large pores are about $15 \mathrm{~nm}$. After $96 \mathrm{~h}$ of dealloying, ligaments increase up to about $200-500 \mathrm{~nm}$ and collapse occurs in many areas, resulting in the formation of large pores (100-200 nm). Visible nanoporous structure coarsening can be seen with the increase of dealloying time, indicating that the nanoflowerpot size can be readily tailored by controlling the dealloying time.

The chemical compositions of the dealloyed samples are measured by EDS and the results are summarized in Table 1. The $\mathrm{Ti}$ content first decreases from 66.7 at $\%$ to 14.7 at $\%$ after $1 \mathrm{~h}$ of dealloying, then goes down to 1.0 at $\%$ after $10 \mathrm{~h}$ of dealloying. Finally, it decreases to 0.5 at $\%$ after $96 \mathrm{~h}$ of corrosion. The gradually decrease of the $\mathrm{Ti}$ content and the coarsening of the NPC structure with the dealloying time suggest that the selective dissolving of $\mathrm{Ti}$ and the uphill diffusion of $\mathrm{Cu}$ carry through simultaneously the whole dealloying process.

Due to the fine and uniform structure, the NPC prepared by dealloying the $\mathrm{Ti}_{2} \mathrm{Cu}$ amorphous alloys for $10 \mathrm{~h}$ was chosen as the flowerpot to grow Au flowers. The NPC was immersed into a $0.5 \mathrm{mM} \mathrm{HAuCl}_{4}$ solution for 20, 40, and $60 \mathrm{~min}$ and the samples are named as NPC-G 1 number, NPC-G 2 number, and NPC-G 3 number, respectively. The SEM images of the NPC-G samples are shown in Figure 3 and the corresponding EDS results are summarized in Table 2. As shown in Figures 3(a) and 3(b), after 20 min of immersion, original bicontinuous nanoporous structure can barely be seen. Highly dispersed Au flowers with a size of 200-300 nm appear. The EDS results show that the sample contains 87.24 at $\%$ of $\mathrm{Au}$, indicating the formation of NPC-G structure. After 40 min of immersion, a large number of Au nanoflowers with a size of about $500 \mathrm{~nm}$ "open" (Figure 3(c)). The flowers 


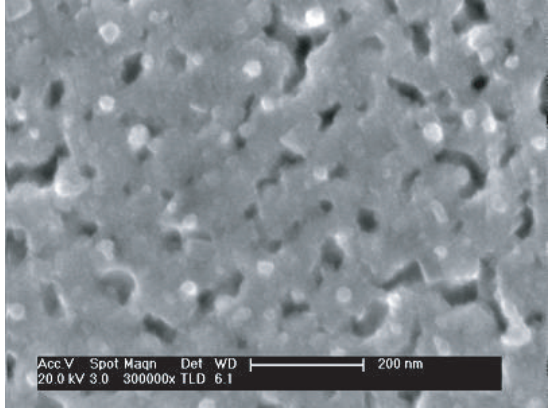

(a)

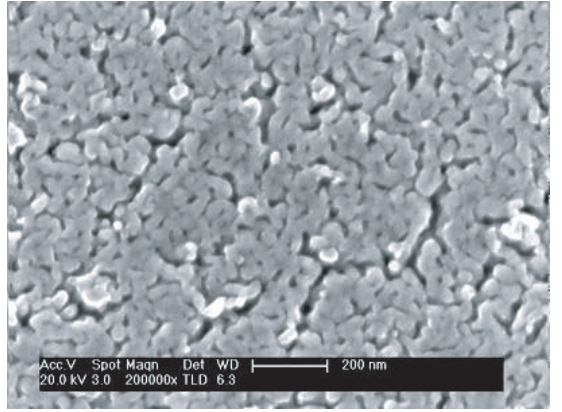

(b)

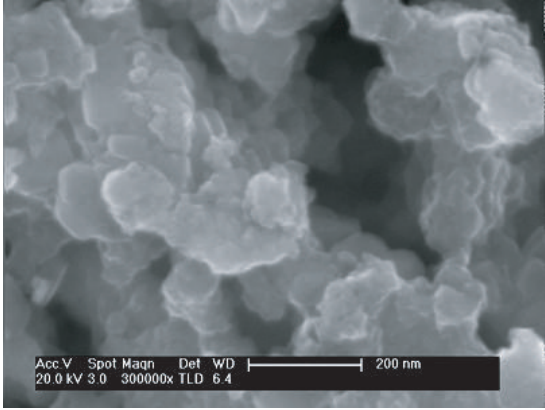

(c)

FIgURE 2: SEM images of NPC 1 number (a), NPC 2 number (b), and NPC 3 number (c).

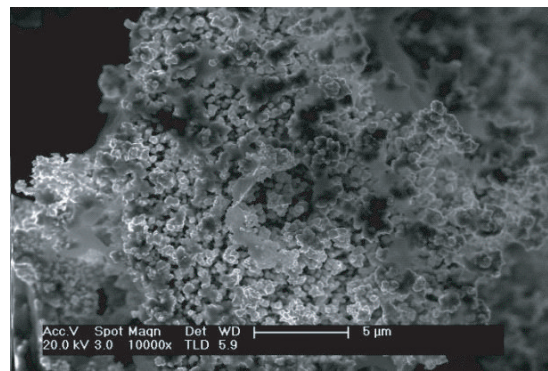

(a)

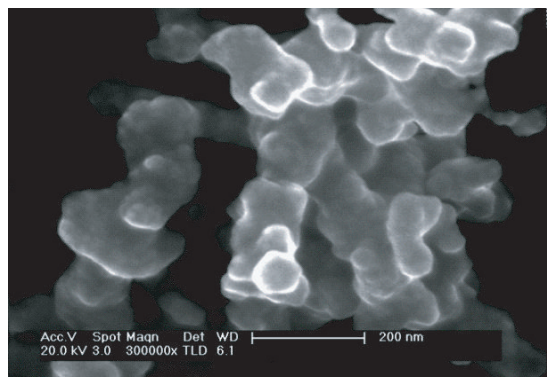

(b)

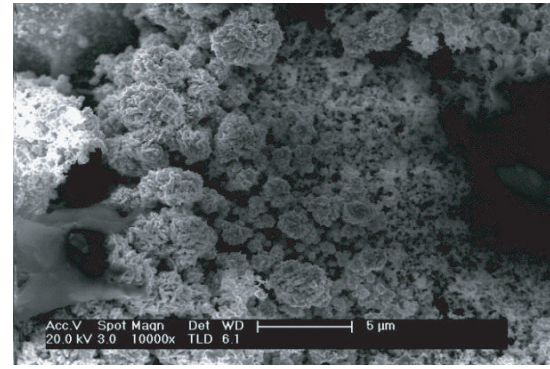

(c)

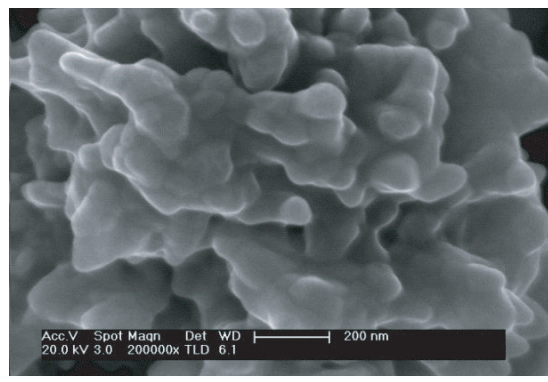

(d)

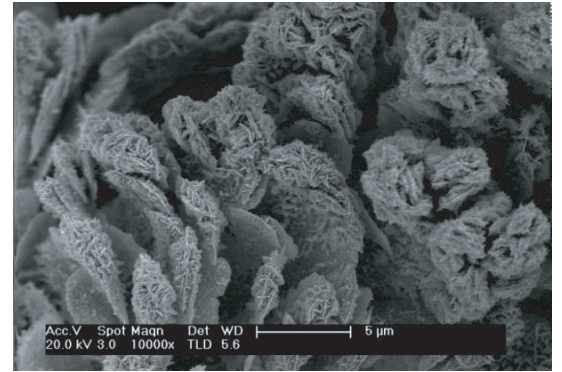

(e)

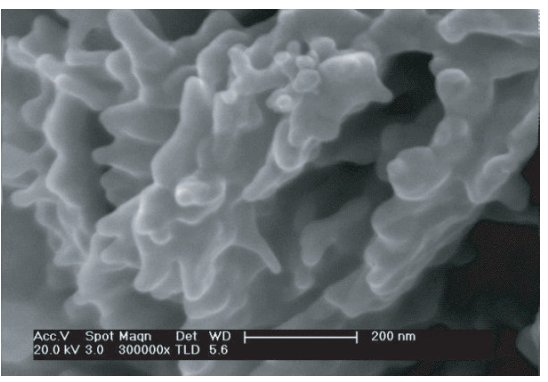

(f)

Figure 3: SEM images of NPC-G 1 number ((a), (b)), NPC-G 2 number ((c), (d)), and NPC-G 3 number ((e), (f)).

are composed by small Au nanoparticles with a size ranging within 100-150 $\mathrm{nm}$ (Figure 3(d)). The further increase of immersion time leads to a slight increase of $\mathrm{Au}$ content to 96.88 at\% and dramatic growth of the Au flowers. As can be seen in Figure 3(e), the flowers are about $5 \mathrm{um}$ in diameter. The detailed morphology observation (Figure 3(f)) shows that the petals are still made by Au nanoparticles, indicating that the growth mechanism of Au is the same as that in NPCG 2 number. Thus, the planting of Au nanoflowers on NPC may be divided into two steps: seeding and growing. Parts of the $\mathrm{Cu}$ atoms on the NPC surface are firstly replaced by $\mathrm{Au}$ according to the replacement reaction: $3 \mathrm{Cu}+2 \mathrm{HAuCl}_{4}=$ $3 \mathrm{CuCl}_{2}+2 \mathrm{HCl}+2 \mathrm{Au}$. As the reaction time increases, all the $\mathrm{Cu}$ atoms on the surface of the NPC are replaced. However, the rapid formation of nanoporous Au provides the Au atoms high surface energy, which may drive the diffusion of $\mathrm{Au}$ towards an up-hill way. As a consequence, Au nanoparticles can form. Due to the Ostwald Ripening, the nanoparticles agglomerate, making the flower growing and open. Due to the high porosity of the NPC formed by dealloying amorphous alloy, the Au nanoflowers are arranged in a highly dispersive way, providing large number of active points which may benefit the catalytic reaction.

The electrocatalytic activities of the NPC-G towards glucose electrooxidation were characterized by $\mathrm{CV}$ curves in $0.1 \mathrm{~mol} / \mathrm{L} \mathrm{KOH}$ alkaline aqueous solutions with and without $50 \mathrm{mM}$ glucose (Figure 4). When compared with that in $\mathrm{KOH}$ solution, the $\mathrm{CV}$ curves in $\mathrm{KOH}+$ glucose solutions exhibit an extra current density hump in the potential range of $-0.4-0.6 \mathrm{~V}$ during the positive scan, where glucose oxidation, including the absorption of $\mathrm{OH}^{-1}\left(\mathrm{Au}+\mathrm{H}_{2} \mathrm{O}=\mathrm{Au}(\mathrm{OH})_{\mathrm{ads}^{1-x}}+\right.$ $\mathrm{H}^{+}+x \mathrm{e}^{-}$) and the oxidation of glucose (the interaction between the hemiacetal group of glucose molecules and 


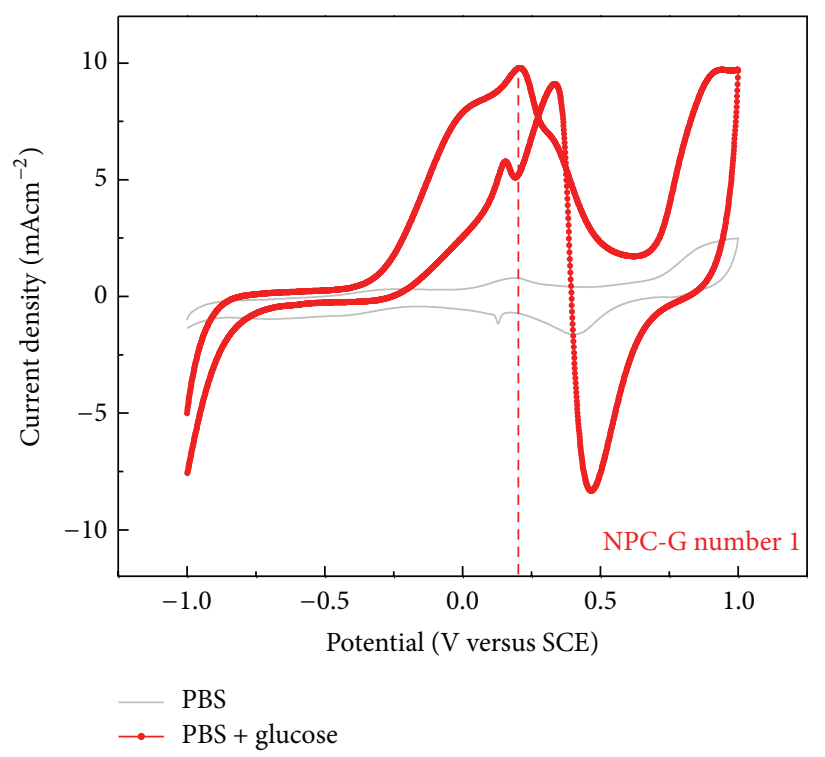

(a)

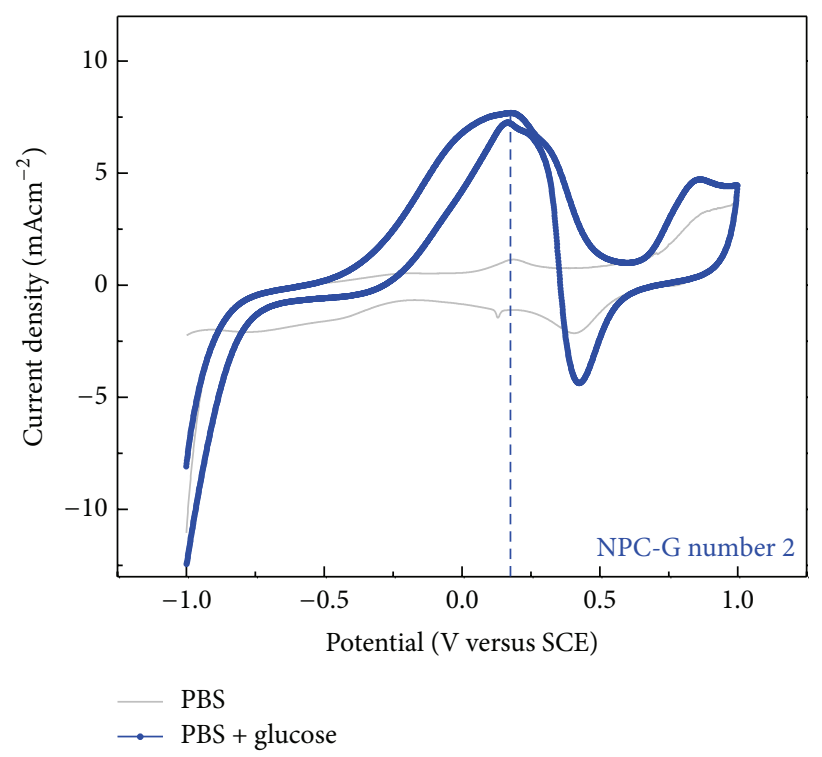

(b)

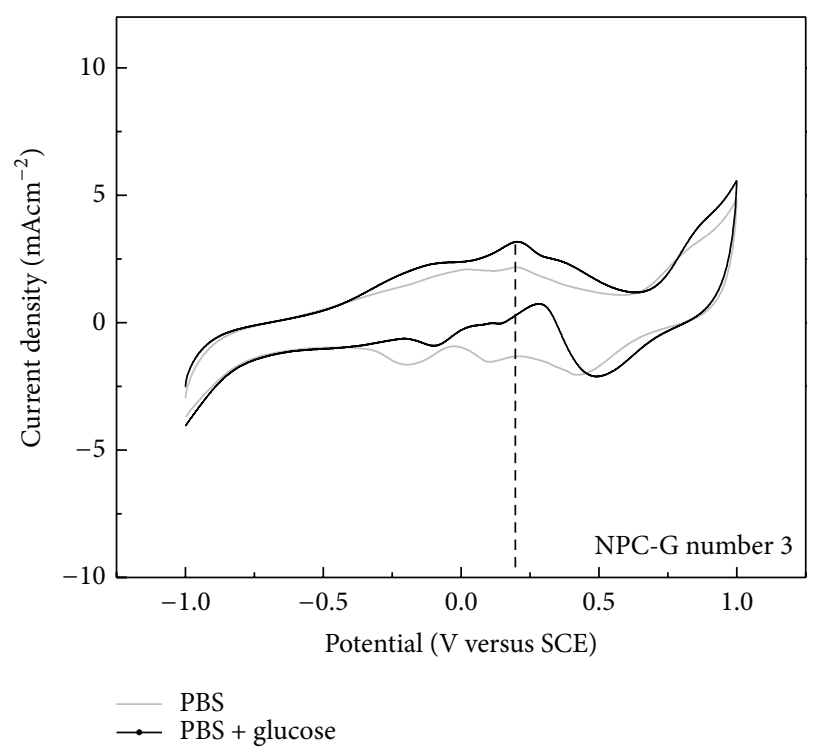

(c)

Figure 4: CV curves of the NPC-G samples in in $0.1 \mathrm{~mol} / \mathrm{L} \mathrm{KOH}$ alkaline aqueous solutions with $50 \mathrm{mmol} / \mathrm{L}$ glucose, scan rate $0.05 \mathrm{~V} / \mathrm{min}$, versus SCE.

$\left.\mathrm{Au}(\mathrm{OH})_{\mathrm{ads}}\right)$, takes place on the surface of the NPC-G samples. The peak position is at about $0.2 \mathrm{~V}$, agreeing with the reported data on NPG and Au nanoparticles [13-17]. The current density value of the peak is $9.8 \mathrm{~mA} / \mathrm{cm}^{2}, 7.6 \mathrm{~mA} / \mathrm{cm}^{2}$ a, and $3.2 \mathrm{~mA} / \mathrm{cm}^{2}$ for NPC-G 1 number, NPC-G 2 number, and NPC-G 3 number, respectively. The current peak density of NPC-G 1 number higher than that of the other NPC-G samples indicates that NPC-G 1 number has the highest catalytic activity. Therefore, NPC-G 1 number is chosen for the stability test and the result is shown in Figure 5. CV curves of a NPG sample with a characteristic pore size of $10 \mathrm{~nm}$ are also involved for comparison. In the case of NPG, the oxidation peak current value drops rapidly, decreasing to $85.7 \%$ after one hundred cycle. Meanwhile, the oxidation peak (potential) shift with the increasing scans can be vividly seen. For NPC-G 1 number, neither peak shift nor peak current density decrease can be observed, indicating that NPC-G has both high catalytic activity and high stability.

\section{Conclusions}

NPC can be fabricated by dealloying the amorphous $\mathrm{Ti}_{2} \mathrm{Cu}$ alloy in $0.03 \mathrm{M} \mathrm{HF}$ electrolytes. The characteristic pore size and ligament size of the NPC can be readily tailored by controlling the dealloying time. The as-prepared NPC provides fine nanoflowerpots to form highly dispersed $\mathrm{Au}$ 


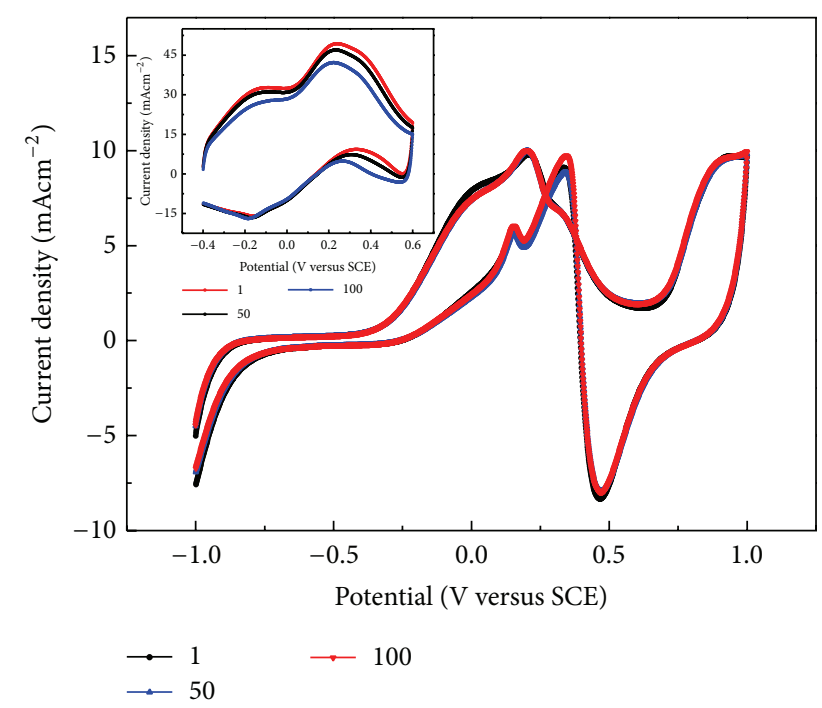

FIGURE 5: CV curves of NPC-G2 number before and after 100 potential cycles in $0.1 \mathrm{~mol} / \mathrm{L} \mathrm{KOH}$ alkaline aqueous solutions with $50 \mathrm{mmol} / \mathrm{L}$ glucose, scan rate $0.05 \mathrm{~V} / \mathrm{min}$. The inset is the $\mathrm{CV}$ curves of NPG during 100 potential cycles in the same conditions, versus SCE.

nanoflowers. The NPC-G structure exhibits both high catalytic activity and stability towards the oxidation of d-glucose, indicating that the amorphous alloys are ideal precursors to form nanoflowerpot which can grow functional nanoflowers.

\section{Conflict of Interests}

The authors declare that there is no conflict of interests regarding the publication of this paper.

\section{Acknowledgments}

This work is supported by the Project sponsored by the National Science Foundation of China (51001026), the Project sponsored by SRF for ROCS, SEM (6812000013), the Project sponsored by Nanjing for ROCS (7912000011), Opening Project of Jiangsu Key Laboratory of Advanced Metallic Materials (AMM201101), and the Fundamental Research Funds for the Central Universities (3212002205, 3212003102).

\section{References}

[1] A. Inoue, "Stabilization of metallic supercooled liquid and bulk amorphous alloys," Acta Materialia, vol. 48, no. 1, pp. 279-306, 2000.

[2] W. H. Wang, C. Dong, and C. H. Shek, "Bulk metallic glasses," Materials Science and Engineering R: Reports, vol. 44, no. 2, pp. 45-89, 2004.

[3] I. Akihisa, "Stabilization of supercooled liquid and openingup of bulk glassy alloys," Proceedings of the Japan Academy B: Physical and Biological Sciences, vol. 73, no. 2, pp. 19-24.

[4] G. Kumar, H. X. Tang, and J. Schroers, "Nanomoulding with amorphous metals," Nature, vol. 457 , no. 7231, pp. 868-873, 2009.
[5] J. Erlebacher, M. J. Aziz, A. Karma, N. Dimitrov, and K. Sieradzki, "Evolution of nanoporosity in dealloying," Nature, vol. 410, no. 6827, pp. 450-453, 2001.

[6] T. Fujita, L.-H. Qian, K. Inoke, J. Erlebacher, and M.-W. Chen, "Three-dimensional morphology of nanoporous gold," Applied Physics Letters, vol. 92, no. 25, Article ID 251902, 2008.

[7] X. Ge, R. Wang, P. Liu, and Y. Ding, "Platinum-decorated nanoporous gold leaf for methanol electrooxidation," Chemistry of Materials, vol. 19, no. 24, pp. 5827-5829, 2007.

[8] Z. Yi, X. Tan, G. Niu et al., "Facile preparation of dendritic Ag-Pd bimetallic nanostructures on the surface of $\mathrm{Cu}$ foil for application as a SERS-substrate," Applied Surface Science, vol. 258, no. 14, pp. 5429-5437, 2012.

[9] J. Erlebacher, "An atomistic description of dealloying porosity evolution, the critical potential, and rate-limiting behavior," Journal of the Electrochemical Society, vol. 151, pp. 614-626, 2004.

[10] J. Yu, Y. Ding, C. Xu, A. Inoue, T. Sakurai, and M. Chen, "Nanoporous metals by dealloying multicomponent metallic glasses," Chemistry of Materials, vol. 20, no. 14, pp. 4548-4550, 2008.

[11] X. Y. Lang, H. Guo, L. Y. Chen et al., "Novel nanoporous Au-Pd Alloy with high catalytic activity and excellent electrochemical stability," Journal of Physical Chemistry C, vol. 114, no. 6, pp. 2600-2603, 2010.

[12] X. Luo, R. Li, Z. Liu et al., "Three-dimensional nanoporous copper with high surface area by dealloying $\mathrm{Mg}-\mathrm{Cu}-\mathrm{Y}$ metallic glasses," Materials Letters, vol. 76, pp. 96-99, 2012.

[13] Z. Liu, L. Huang, L. Zhang, H. Ma, and Y. Ding, "Electrocatalytic oxidation of d-glucose at nanoporous $\mathrm{Au}$ and $\mathrm{Au}-\mathrm{Ag}$ alloy electrodes in alkaline aqueous solutions," Electrochimica Acta, vol. 54, no. 28, pp. 7286-7293, 2009.

[14] B. K. Jena and C. R. Raj, "Enzyme-free amperometric sensing of glucose by using gold nanoparticles," Chemistry, vol. 12, no. 10, pp. 2702-2708, 2006.

[15] T. Fujita, T. Tokunaga, L. Zhang et al., "Atomic observation of catalysis-induced nanopore coarsening of nanoporous gold," Nano Letters, vol. 3, Article ID 3015, 2014.

[16] Y. Bai, W. Yang, Y. Sun, and C. Sun, "Enzyme-free glucose sensor based on a three-dimensional gold film electrode," Sensors and Actuators B: Chemical, vol. 134, no. 2, pp. 471-476, 2008.

[17] X.-Y. Lang, H.-Y. Fu, C. Hou et al., "Nanoporous gold supported cobalt oxide, microelectrodes as high-performance electrochemical biosensors," Nature Communications, vol. 4, no. 2169, pp. 1-8, 2013. 

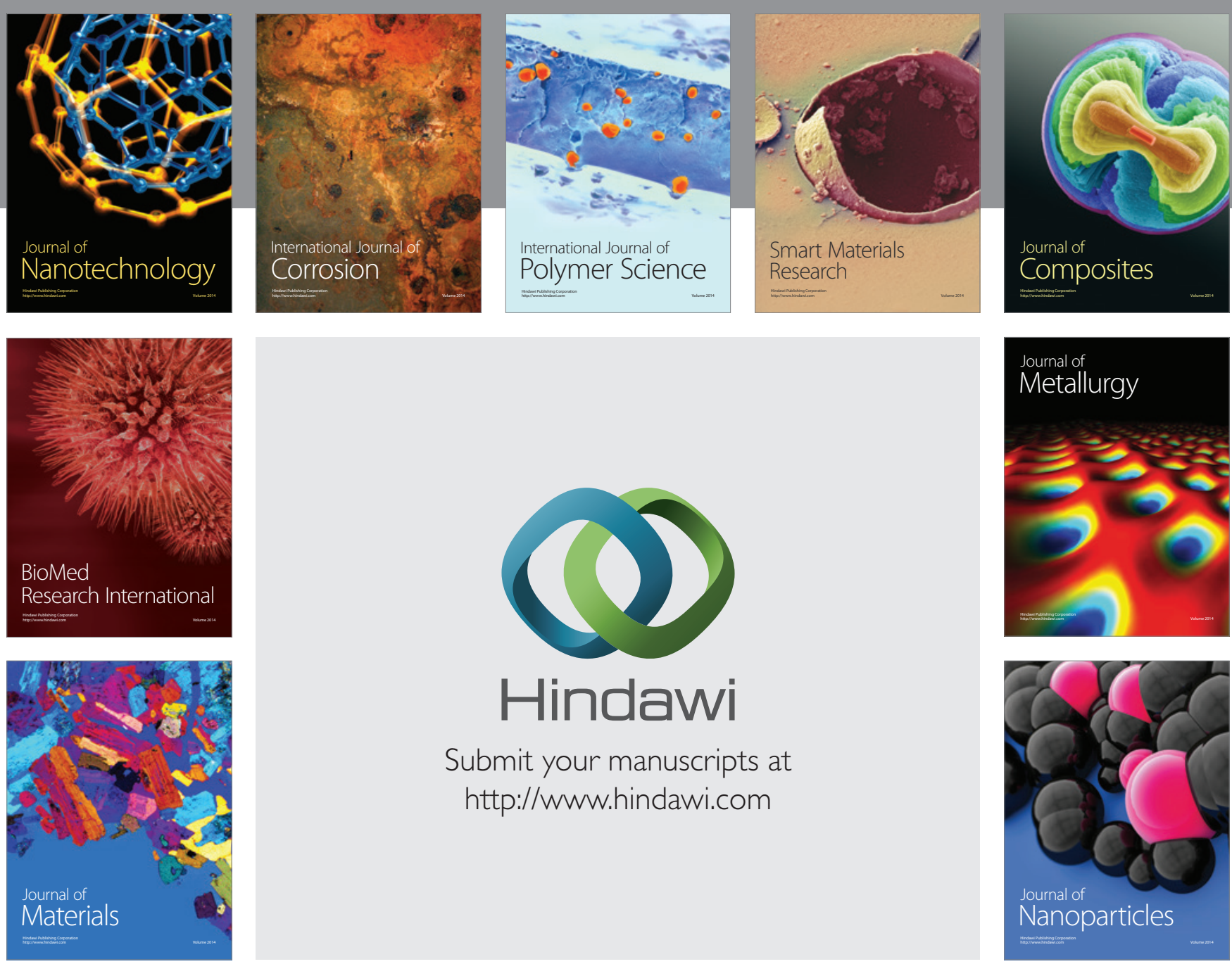

Submit your manuscripts at http://www.hindawi.com
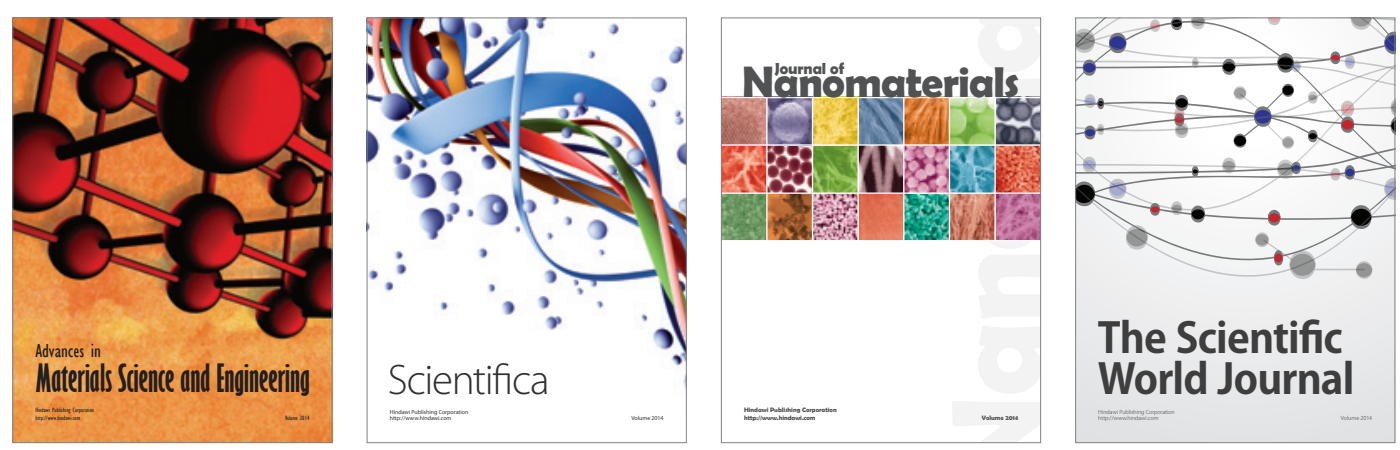

\section{The Scientific World Journal}
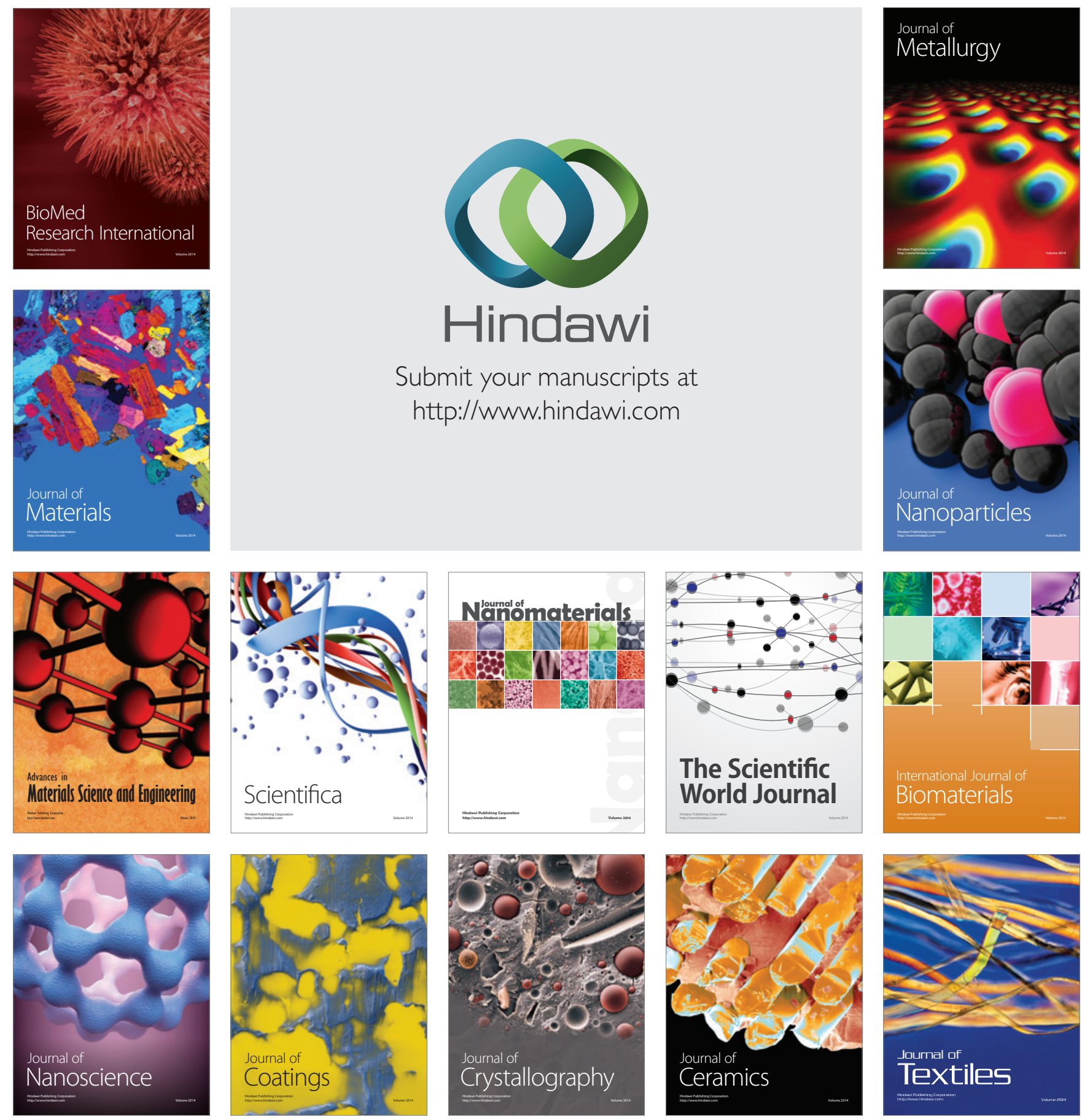